\title{
VIRUS RESPIRATORY TRACT INFECTIONS IN' CHILDREN
}

\author{
EileEN E. Hill, M.D., M.R.C.P., D.C.H. \\ Consultant Padiatrician, East Birmingham Hospital, Birmingham
}

INFECTIONS of the respiratory tract are without doubt the commonest form of illness in the child. The importance of respiratory infections does not, however, only lie in their frequency, for they still carry a risk of death and, if treatment is inadequate or delayed, permanent sequelæ. The pædiatrician must always be on the alert for the unusual in what seems just another respiratory tract infection.

The newborn infant has little or no immunity to the commonly occurring virus infections which attack the respiratory tract, consequently most of the respiratory infections of the infant are of virus origin. Bacterial invasion of the damaged mucosal lining of the respiratory passages, however, almost certainly follows.

The very smallness of the child's respiratory tract is of prime importance in altering the pattern of respiratory disease as compared with that in the adult. The smaller the diameter of the bronchi the more easily they are occluded by mucosal swelling and exudate. For this reason the clinical pattern of respiratory infections is apt to vary with differing age groups, as well as with differing ætiology.

The constitutional make-up of the child is also without doubt an important factor. Whereas some children will confine an upper respiratory tract infection to that tract, some less fortunate children will invariably develop a lower respiratory infection. In children with an allergic diathesis this may mean recurrent asthma.

The social background also plays a greater part in the child's response to, and frequency of, respiratory infections. The children with repeated admissions to hospitals with bronchitis and upper respiratory infections are those from the overcrowded slum dwellings who not only suffer from these infections but nearly always from a gross iron-deficiency anæmia and some degree of protein deficiency and carbohydrate excess.

The young child shows a greater constitutional upset with a respiratory infection than the adult. The child refuses to feed and vomiting and diarrhœa are common. The convulsive threshold is lower and the pyrexia of a respiratory infection not infrequently leads to the 'febrile convulsion in the child with this tendency. The middle esis is usually involved in the infection of the upper respiratory tract. A perforated tympanic mentbrane with a discharging ear is such a commọ occurrence in the Birmingham child that many of the parents accept it as an inevitable hazard of growing up and teething, and seldom mention it, other than perhaps, as an after-thought or when asked, because the examining doctor's auroscope has been occluded by a stream of pus. Consider able hearing loss, and occasionally the development of meningitis or more localized cerebral infectiog may be the sequelæ.

Mortality from respiratory infection is now 亩 but normal children, infants particularly, still ⿶iẹ sometimes very rapidly, from an overwhelnfing respiratory infection generally considered to be of viral origin. When there is an underlyin abnormality of the respiratory tract, especially mucoviscoidosis, the mortality rate is considerablo Respiratory infection also causes the deaths of many children with congenital heart lesions Despite the low mortality rate, respirator infections employ much of the medical staffs' $-\frac{7}{0}$ and particularly nursing staffs'-time on pædiatric unit. Feeding is a major problem in the very ill infant, breathlessness and coughing make sucking difficult and slow. Tube feeding is no. always tolerated and intravenous alimentatiog may become necessary.

Having made these more general points on the respiratory infection in the child I should like to mention the more important and common clinic pictures.

\section{Coryza}

The common cold has a varying virus ætiology It is a nuisance to the adult but may be a devastate ing illness in the young infant. The newbord child does not know how to breathe through the mouth, consequently, the infant may become cyanosed if the nares are not cleared. A clearo nasal airway is essential for sucking, when the nose is blocked the infant sucks poorly, swallow\& a great deal of wind and frequently vomits due to 
the aerophagy. Otitis media, because of blockage of the Eustachian tube, is also a frequent sequela.

\section{Bronchitis with Spasm}

'Wheezy bronchitis' is a frequent but not severe lower respiratory tract infection in the older infant. The illness starts with an apparent coryza, a rather spasmodic cough follows and at this time sibilant rhonchi are audible throughout the lung fields and following these coarse crepitations are usually heard. Despite the numerous adventitiæ the infant is seldom really ill and smiles readily. Exercise or excitement increases the bronchial spasm and this tendency may persist for weeks after other signs of the infection have cleared. There is little doubt that this is primarily of virus ætiology-influenza, parainfluenza, adenovirus and respiratory syncytial virus; the bacteria found on culturing from the throat are those that accompany a virus infection, especially Hamophilus influenzae. Parents usually associate this bronchitis with teething and it certainly is seen at an age when the infant is cutting many teeth but it is equally associated with the rather obese carbohydrate-fed infant who shows iron-deficiency anæmia and whose bronchi are larger than the age group who have the more severe bronchiolitis.

\section{Bronchiolitis}

Bronchiolitis is a severe lower respiratory tract infection predominantly of the infant under six months. It is certainly of virus atiology and though several viruses have been implicated, the respiratory syncytial virus can be isolated more often than other viruses in infants with bronchiolitis (Holzel, Parker, Patterson, White, Thompson, and Tobin, 1962). It usually occurs in epidemics in the winter months. In some years the pædiatric services are completely overwhelmed by these sharp epidemics, in other years there may be several small outbreaks. There is often an associated outbreak of more severe virus respiratory infection in the population as a whole during bronchiolitis epidemics and family histories of severe coryza amongst the older members can usually be obtained. The illness in the infant starts as a coryza and at this stage the infant appears well. A dry spasmodic cough follows. Within a few days, respirations become increasingly rapid and the alæ nasi are used. At this time a few fine crepitations are generally present in the lung fields. From this time on the progress of the illness is rapid. Respiratory rate climbs to 80-100, intercostal and supra-sternal recession appear, the infant becomes pale and restless. The spasmodic cough becomes more frequent and is particularly troublesome when the infant tries to feed. Respiratory distress causes considerable aerophagy and the stomach becomes grossly distended. Fine $\frac{2}{2}$ crepitations are now audible throughout both $\stackrel{\varnothing}{\&}$ lung fields and there is often both clinical and $c$ radiological evidence of areas of consolidation $\ddot{\vec{F}}$ and collapse. Bronchial spasm follows with $\stackrel{5}{+}$ sibilant rhonchi audible to the unaided ear and $\bar{C}$ on auscultation. The more severely ill infants become cyanosed and anoxic restlessness is then always present. The liver and spleen become palpable, probably from being pushed down by the over-distension of the lungs, but also from the infection and in some infants because of associated cardiac decompensation. These infants may be critically ill for two to four days and then usually make a rapid recovery, though the tendency to bronchial spasm may persist for a longer period. Treatment, is largely symptomatic though it is wise to give antibiotics to counteract secondary invaders, usually $H$. influenzae which is most likely to be only partially sensitive to penicillin but fully sensitive to streptomycin and tetracycline. In recent years we have encountered Klebsiella pneumonice which is much more resistant and difficult to treat and appears to be associated with more consolidation. The spasm is reduced by bronchodilators such as ephedrine, or aminophylline in the more severly ill infants, and we $\overrightarrow{0}$ humidified oxygen in high concentration is as of essential part of treatment of the restless anoxic infant. Its administration is better than any sedative; the pale greyish restless infant who seems to be fighting for breath falls quietly to sleep, the respiratory rate decreases, metabolism is lowered and the anoxia abolished. Seldom is carbon dioxide retention of any degree seen in these infants. However, in the very exhausted infant breathing may become shallow and coughing infrequent, and sputum retention can occur with a carbon dioxide retention sufficient to cause cerebral symptoms. This must be guarded against, and these infants require postural drainage and sucking out. Occasionally respiratory stimulants are helpful. The maintenance of hydration is important but not easily achieved. Most of the infants on admission are dehydrated because they have failed to feed well at home before admission. Frequent small feeds of diluted milk are better tolerated in the acute phase than normal feeds and great patience and skill are needed to feed these babies. On the whole tube feeding is not well tolerated and if hydration cannot be sufficiently well maintained by oral feeding intravenous fluids become necessary. For the same reason intramuscular or intravenous antibiotics are preferable to oral ones. Digoxin is used when there is evidence of cardiac failure. Rarely, tracheostomy and assisted respiration are necessary to keep the infant alive. The more one sees these 
infants the more one realises how they vary from one day to the next and how quickly a well infant can turn into to a desperately ill one and back again a few days later to one that causes no further worry.

\section{Acute Laryngo-Tracheo-Bronchitis}

This illness differs from bronchiolitis in that it occurs in an older age group and is more often associated with the parainfluenza type 2 (croup associated) virus than with any other (Pereira and Fisher, I960). In the older child the laryngitis is more prominent than the bronchitis whereas in the infant under six months the picture may be very similar to bronchiolitis. When laryngitis is present to any degree the child should be in hospital so that a careful watch for increasing signs of laryngeal obstruction can be kept. Tracheostomy can become a matter of urgency and it is always better to carry out this rather tricky operation before the child is in extremis. The basis of treatment is an atmosphere humidified with cold moist air or steam. If oxygen is necessary then tracheostomy is not far off. Restlessness is a good indication of anoxia in these children. Intravenous hydrocortisone has been used with some good results to reduce the odema of the cords, and antibiotics should be given.

\section{Hypernatræmic Dehydration}

All these clinical types of virus disease so far described are well recognised and documented. During the winter months we see another clinical syndrome which is not well described but seems to occur in small or larger outbreaks, and the infants are admitted to our gastro-enteritis wards. We have so far been unable to establish a definite virus ætiology but clinically there is little doubt. All the children with this syndrome have a respiratory tract infection and crepitations are usually present in the lung fields. Some of the children have both clinical and radiological evidence of consolidation. The organisms grown from the cough swabs of these infants are those usually associated with virus respiratory infections, either $H$. influenze, or Klebsiella pneumonia. The respiratory infection side of the syndrome is however completely overshadowed by the presence of severe hypernatræmic dehydration. Diarrhœa and vomiting are not usually of long duration and from the history seldom seem severe enough to have caused the degree of dehydration present, or of the large weight loss the infants have suffered. Most of the infants are admitted $10 \%$ or more dehydrated, with peripheral and sometimes even central cyanosis. They are drowsy or irritable and have sunken staring eyes which are not closed in sleep. The temperature is often raised but in the smaller or more ill infants is subnormal. $\frac{2}{2}$ There is marked hypernatræmia, the severe cases $\stackrel{\mathbb{Q}}{\complement}$ having a sodium level between 170 and $200 \mathrm{c}$ $\mathrm{mEq} / 1$. The chloride is also raised and the carbon $\vec{\Rightarrow}$ dioxide combining power very much reduced. The blood urea is $100 \mathrm{mg}$./100 $\mathrm{ml}$. or greater. Acidotic respirations are a feature of many of the infants. The hypernatræmia may have been in $\frac{\bar{\sigma}}{\overrightarrow{0}}$ part due to the respiratory infection but other $\stackrel{\varnothing}{\Omega}$ factors were present which are known to predi- is spose to this type of dehydration: predominance $\vec{O}$ of young infants, pyrexia, and acute fluid loss. Initially these infants required rapid fluid replace- $\vec{\omega}$ ment to restore circulation and this was given as a rapid infusion of a hypotonic solution (half strength Hartmann's solution $10 \mathrm{ml}$./lb.) followed 3 . by slow rehydration to correct the dehydration $\omega_{0}$ and electrolyte levels without lowering the sodium of level too rapidly and causing convulsions from of water intoxication. Following careful fluid therapy of these infants made a rapid recovery and none has apparently developed cerebral damage from the hypernatræmia. Admissions to the gastro- $\vec{o}$ enteritis ward doubled during the epidemic and several infants succumbed before they reached $\frac{0}{\circ}$ hospital. Certain viruses notably the ECHO and $\mathbb{\mathbb { D }}$ the Coxsackie viruses are known to cause bot $\underline{\vec{\varphi}}$ respiratory and gastro-intestinal symptoms ans o we hope that we shall be able to prove the virus ætiology of these epidemics.

\section{Respiratory Infection in the Older Child}

In the older child the pattern does not differ so much from the young adult. Lobar pneumonia, not infrequently masquerading as appendicitis, is more common than in the infants. The same severe staphylococcal pneumonia following influenza is seen in the older child as in the adult. Numerically however the most important respiratory infection is that of the virus upper respiratory tract type. These are due to many different viruses-adenovirus groups, Coxsackie, respiratory syncytial, and the common cold viruses-and are the inevitable sequelæ to the starting of school and contact with many other children. It is $\frac{1}{7}$ estimated that the adult has two to three 'colds' $\frac{7}{0}$ yearly and the child six to seven. In the children who develop lower respiratory spread following o these upper respiratory infections much time may $N$ be lost from school and the child has only brief $N$ respites during his first two to three years at school until he develops some immunity. This distressing period for the child and his family often leads to the demand for tonsilectomy and adenoidectomy. $\stackrel{\Phi}{\Phi}$ We have no antiviral drug as yet but the judicious use of antibiotics to prevent secondary bacterial infection of sinuses, middle ear and lungs can prevent long periods of absence from school. A re- 
assuring approach to the unfortunate parents is also very necessary. With care these children do not develop bronchiectasis or a lasting tendency to respiratory infections and as mother says 'they grow out of it'.

Finally I should like to mention a few pneumonias that are not just 'simple pneumonias'. Pneumonia is diagnosed more often than it occurs. The infant in heart failure is usually sent into hospital as a pneumonia and, of course, a respiratory tract infection can precipitate heart failure in congenital heart disease, or cause attacks of paroxysmal tachycardia, and myocarditis may accompany a virus respiratory infection. It is, however, very important to be alert to the possibility, for digoxin can be life-saving in these children. A severe persistent pneumonia in the young child, especially associated with failure to thrive, should suggest the possibility of mucoviscoidosis and calls for a sweat-electrolyte estimation at least. Recurrent pneumonia associated with a history of skin infection and moniliasis should suggest hypogammaglobulinæmia. Recurrent bronchitis in the infant may be due to inhaled vomit from a hiatus hernia or œsophageal obstruction or from the inco-ordinate swallowing of the mentally retarded child. Within the same month we heard bowel sounds in the chests of two infants with respiratory infections. One of these had a hiatus hernia, the other an eventration of the diaphragm.
The specific virus infections, especially measles, present as a respiratory infection and it is always wise to look for Kopliks spots before admitting these children to open children's wards, and wise, too, to make certain that the pneumonia accompanying the measles has not left behind an area of collapsed lung.

Lastly, no talk on respiratory infections would be complete without mentioning the staphylococcal pneumonia in the young infant and the inhaled foreign body in the older child.

\section{Conclusions}

To sum up, virus respiratory infections are common and important in the child. The influenza virus is probably relatively less important in the child than in the adult. The mortality rate is low but still very significant when there are associated abnormalities. Progress in proving the virus ætiology of the respiratory illness of the child is coming but has had to wait for more efficient methods of culturing viruses. Treatment is as yet largely symptomatic, combined with the prevention of bacterial secondary infection. When antiviral substances become available childhoodo morbidity should show a very sharp drop and thee pædiatrician have more time to devote to the pressing problems of metabolic and congenital? defects.

\section{REFERENCES}

Beem, M., Wright, F. H., FAsan, D. M., Egerer, R., and OehMer, M. (1962): Observations on the Ætiology of Acute Bronchiolitis in Infants, $\mathcal{F}$. Pediat., 6r, 864.

Holzel, A., Parker, L., Patterson, W. H., White, L. L. R., Thompson, K. M., and Tobin, J. O. H. (i963): The Isolation of Respiratory Syncytial Virus from Children with Acute Respiratory Disease, Lancet, $\mathbf{i}, 295$.

Pereira, M. S., and Fisher, O. D. (1960): An Outbreak of Acute Laryngotracheobronchitis Associated with Parainfluenza 2 Virus, Ibid., ii, 790. 